$$
\begin{aligned}
& \text { مقاومت جـند گانه، اشرشيا كلى توليدكننده بتالاكتامازهاى طيف گسترده per و ptx-m، } \\
& \text { جeb }
\end{aligned}
$$

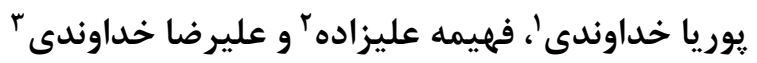

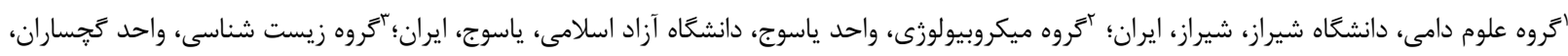

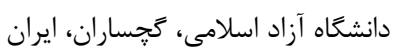

$$
\begin{aligned}
& \text { مسئول مكاتبات: عليرضا خداوندى، khodavandi@iaug.ac.ir }
\end{aligned}
$$

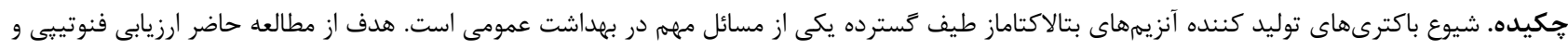

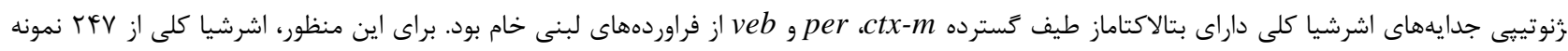

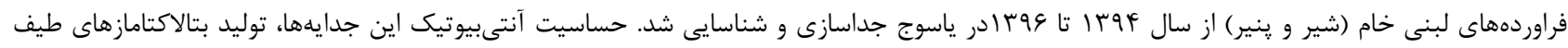

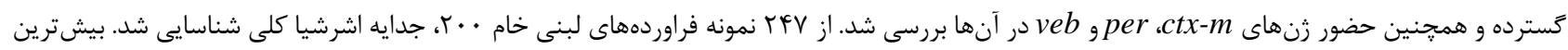

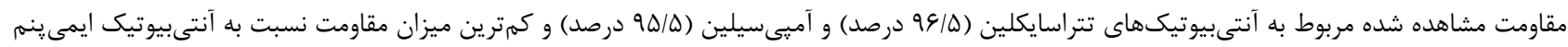

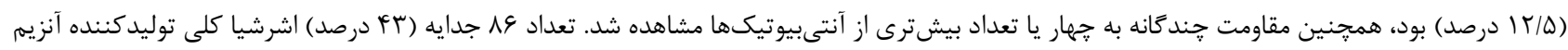

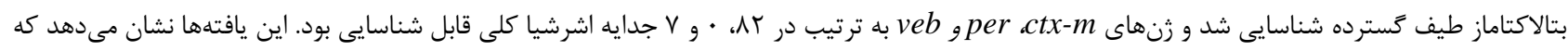

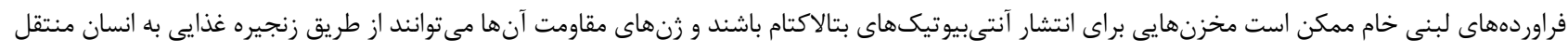

$$
\text { وازمهاى كليدى. آنتىبيوتيك، باكترى، ينير فراورىنشده، زن، شير خام }
$$

\title{
The multidrug resistance and production of extended-spectrum beta- lactamases $c t x-m$, per and ver in Escherichia coli isolates derived from raw dairy samples
}

\author{
Pouria Khodavandi ${ }^{1}$, Fahimeh Alizadeh $^{2}$ \& Alireza Khodavandi ${ }^{3}$ \\ ${ }^{1}$ Department of Animal Science, Shiraz University, Shiraz, Iran; ${ }^{2}$ Department of Microbiology, Yasooj Branch, Islamic \\ Azad University, Yasooj, Iran; ${ }^{3}$ Department of Biology, Gachsaran Branch, Islamic Azad University, Gachsaran, Iran \\ Correspondent author: Alireza Khodavandi, khodavandi@iaug.ac.ir
}

\begin{abstract}
The occurrence of extended-spectrum beta-lactamases-producing bacteria is an important public health issue. The aim of this study was to investigate phenotypic and genotypic characteristics regarding the presence of extended spectrum $\beta$-lactamase $c t x-m$, per and ver producing Escherichia coli isolated from raw dairy samples. For this purpose, E. coli were isolated from 247 raw dairy samples (milk and cheese) in Yasooj in 2015-2017, and the isolates were screened for antibiotic resistance, extended spectrum $\beta$-lactamase and the presence of $c t x-m, p e r$ and ver. In total, 200 isolates were selected. The highest frequency of resistance in isolates was against tetracycline $(96.5 \%)$ and ampicillin $(95.5 \%)$ antibiotics and the lowest against imipenem (12.5\%), In addition, multidrug resistance against four or more antibiotics was observed in some isolates. Extended spectrum $\beta$-lactamase resistance was detected in 86 isolates (43\%) and $c t x-m$, per and ver genes were detected in 82, 0 and $7 \mathrm{E}$. coli isolates, respectively. These findings demonstrated that raw dairy products may be reservoirs for the dissemination of $\beta$-lactam antibiotics and that resistance genes could be transmitted to humans through the food chain.
\end{abstract}

Key words. antibiotic, bacteria, gene, raw milk, unprocessed cheese

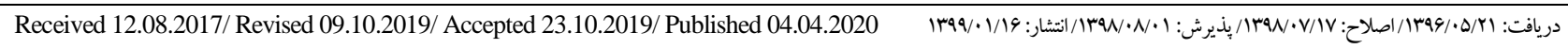


فراوردها، مصرف فراوردههاى لبنى سنتى جايعاه خاص خود را در مقام

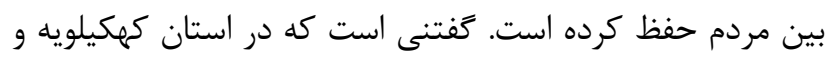

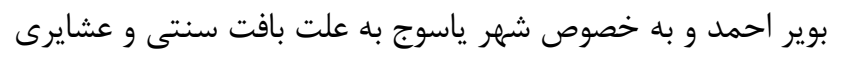

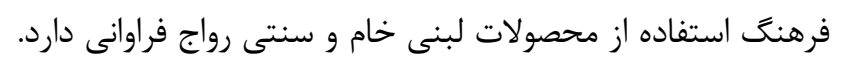

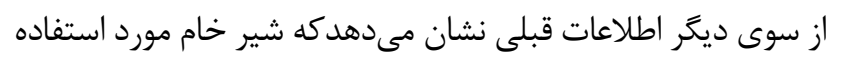

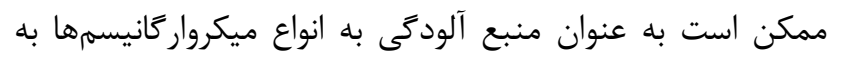

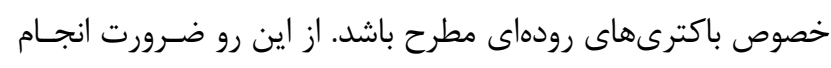

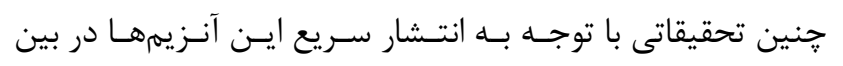

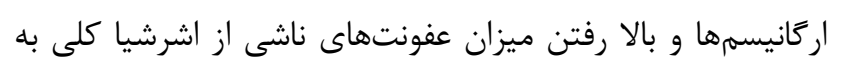

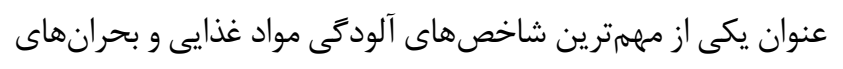

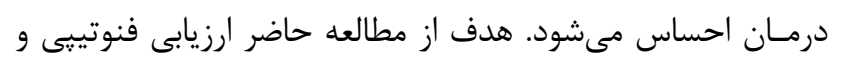

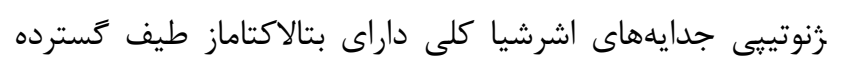

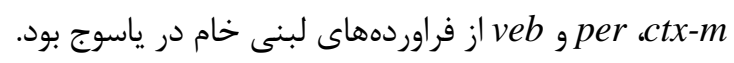

مواد و روشها

ميكروار كانيسمها

در اين مطالعه توصـيفى مقطعىى، تعداد Y TF نمونه فراوردهنهاى

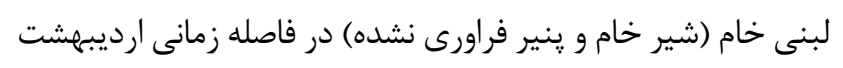

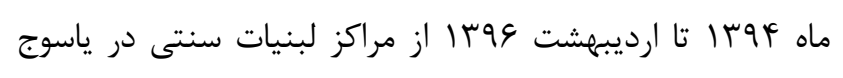

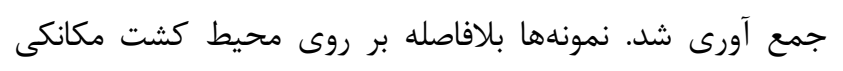
و ائوزين متيلن بلو كائ مكانك (MAC, Merck, Darmstadt, Germany) آكار (EMB, Merck, Darmstadt, Germany) كشت داده

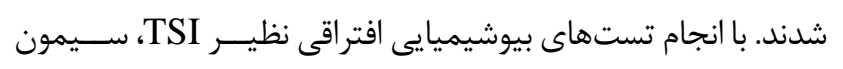

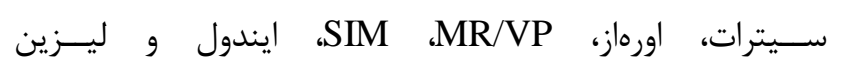

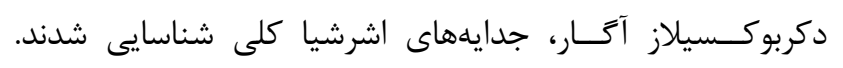

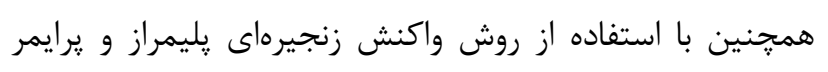
عمومى 16S rRNA (جدول () شناسايى مولكولى جدايههاى

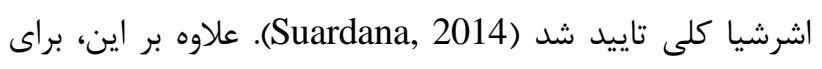

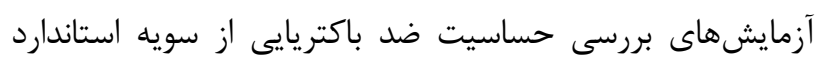

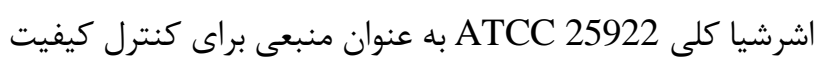

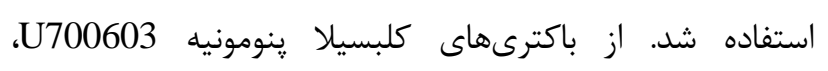

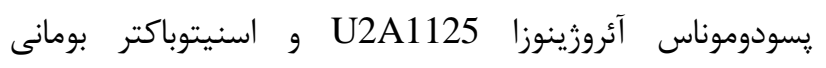

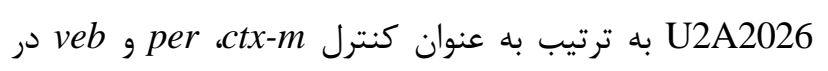
آزمايشهاى تعيين اشرشيا كلى توليدكنـــده بتالاكتاماز طيف كسترده استفاده شد.

آزمون حساسيت سنجى اشرشيا كلى به روش ديسك ديفيوزن

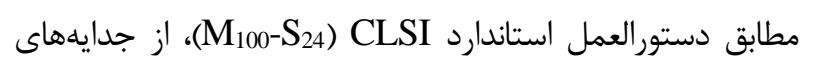

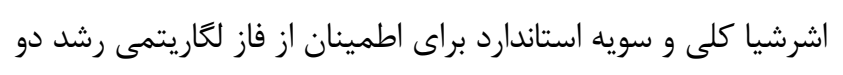

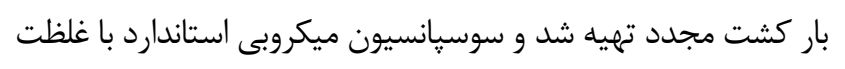

اشرشيا كلى (Escherichia coli) طيف وسيعى از عفونتهاى

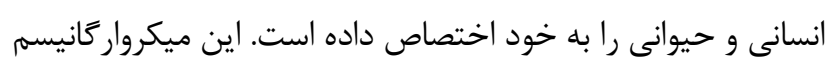

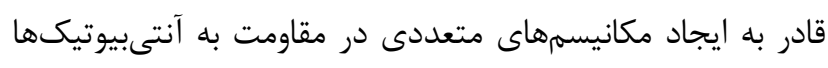

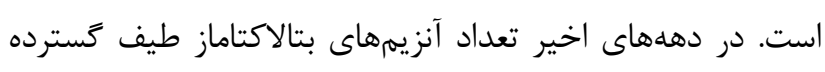

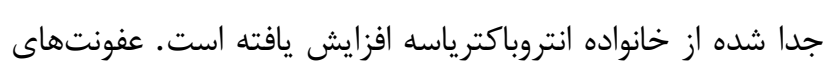

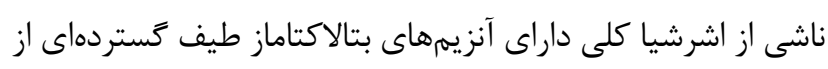

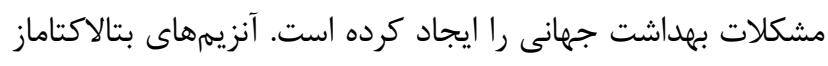

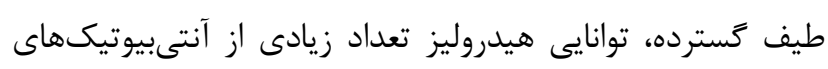

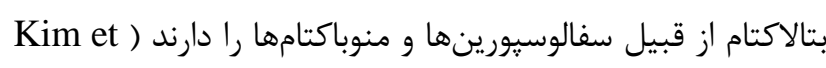
.al., 2007; Schmid et al., 2013; Braun et al., 2016 آنزيمهاى بتالاكتاماز طيف گسترده موجب ايجاد مقاومت خند در باكترىهاى گرم منفى از قبيل انتروباكترياسه شده است. خانواده

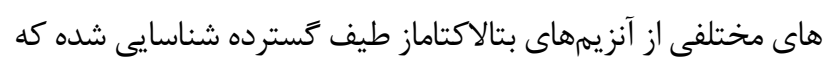

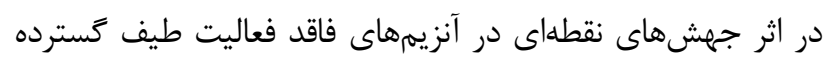

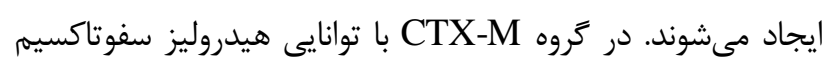

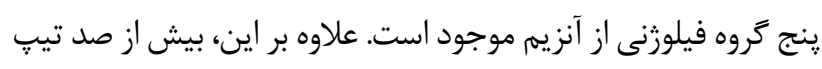

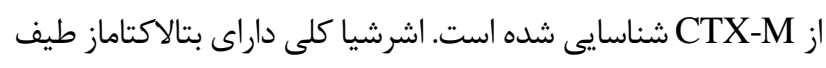
كسترده CTX-M از حيوانات مزارع توليد كننده مواد لبنى و فراوردهـ هaveh et al., ) هاى لبنى خام جداسازى و شناسايى شده / ها

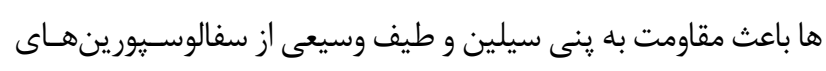

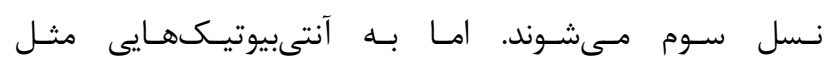

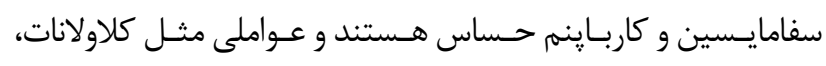

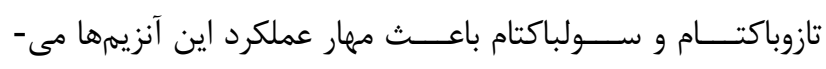
شوند (Rupp \& Fey, 2003). آنزيمهاى بتالاكتاماز طيف كسترده همم بر روى كروموزوم باكترى و همم بر روى يلاسميد يافت شده است آنساز

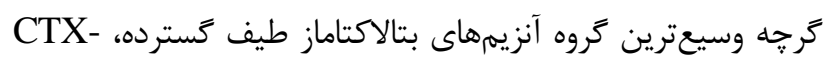

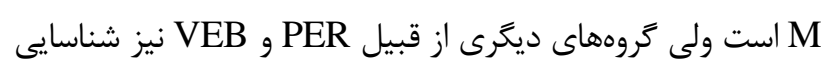

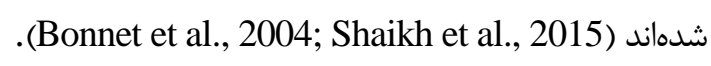
به دليل مصرف بىرويه آنتىبيوتيكها مخصوصا سفالوسيورينها،

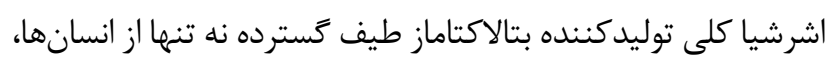

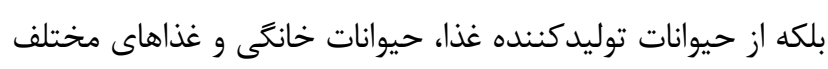

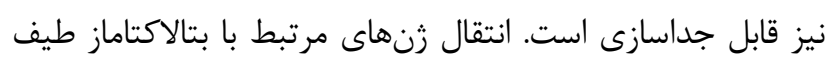

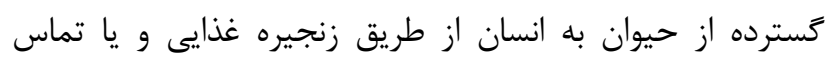

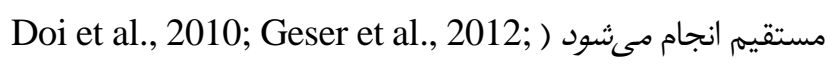
ما مamani et al., 2015; Braun et al., 2016

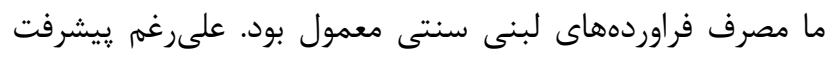

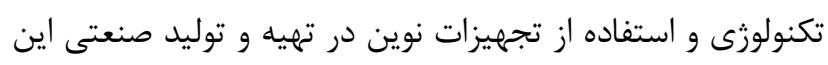


جدول ا- يرايمرهاى اوليكونوكلئوتيد استفاده شده براى واكنش زنجيرهاى يليمراز.

Table 1. Oligonucleotide primers used for PCR.

\begin{tabular}{|c|c|c|c|}
\hline 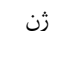 & 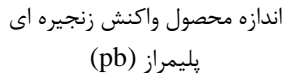 & 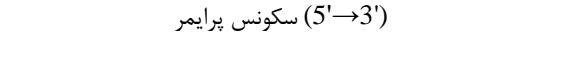 & منابع \\
\hline \multirow[t]{2}{*}{ rRNA } & $\mid r \Lambda$ & Forward: AGAGTTTGATCCTGGCTCAG & Suardana, 2014 \\
\hline & & Reverse: GGTTACCTTGTTACGACTT & \\
\hline \multirow[t]{2}{*}{$c t x-m$} & DFF & Forward: TTTGCGATGTGCAGTACCAGTAA & Edelstein et al., 2003 \\
\hline & & Reverse: CGATATCGTTGGTGGTGCCATA & \\
\hline \multirow[t]{2}{*}{ per } & ז & Forward: AATTTGGGCTTAGGGCAGAA & Jiang et al., 2006 \\
\hline & & Reverse: ATGAATGTCATTATAAAAGC & \\
\hline \multirow[t]{2}{*}{$v e b$} & GKT & Forward: CGACTTCCATTTCCCGATGC & Jiang et al., 2006 \\
\hline & & Reverse: GGACTCTGCAACAAATACGC & \\
\hline
\end{tabular}

اساس استاندارد CLSI ثبت شد. آزمايشها به صورت ب تكرار تكنيكى انجام گرفت و r بار تكرار شد. آزمون تاييدى فنوتييى اشرشيا كلى توليدكننــده بتالاكتاماز

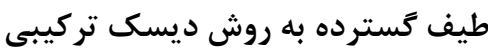

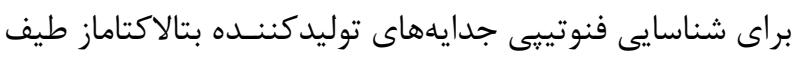

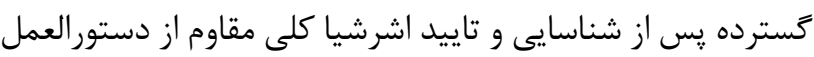
استانداد CLSI استفاده شد. مطابق دستورالعمل، سوسيانسيون معادل نيم مك فارلند تهيه و و يس از زخــش كـردن كامـل

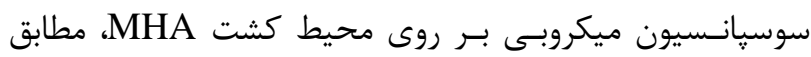

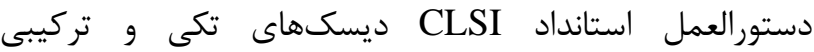
سفوتاكسيم (•r ميكـروزرم/ديسك)، سفوتاكسيم/كلاولانات

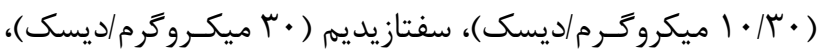

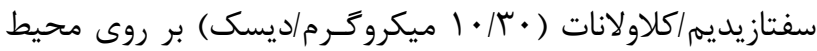
كشت قرار گرفتند ( HiMedia Laboratories, Mumbai, ) - India كراد قطرهاله ممانعت از رشد بر حسب ميلىمتر توسط خط كش

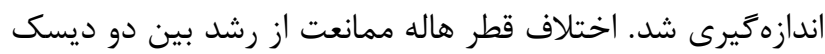

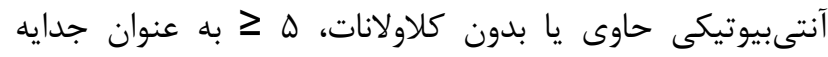
توليدكنـــده بتالاكتاماز طيف گسترده درنظرگرفته شد ( Rawat .\& Nair, 2010; CLSI M $100-\mathrm{S}_{24}$ آزمون تاييدى زنوتييى اشرشيا كلى توليدكننــده بتالاكتاماز طيف كسترده با استفاده از زنهاى براى تاييد زنوتييى اشرشيا كلى توليدكنـــده بتالاكتاماز طيف كسترده، استخراج DNA توسط روش جوشاندن انجام گرفت

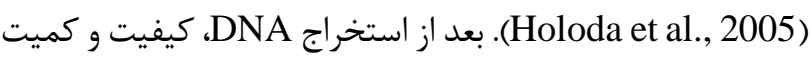
آن با استفاده از اسيكتروفتومترى و زل آكاروز مورد بررسى قرار گرفت.

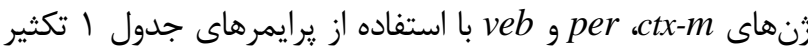

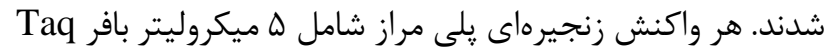
،(Taq buffer, Fermentas, Waltham, MA, USA) I·X

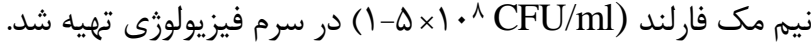
حدود ب-Y كلنى از باكترى به ب ميلى ليتر ازمحيط كشت نوترينت براث استريل اضافه و ورتكس شد. سيس يك بـ بار شستشو داده شد.

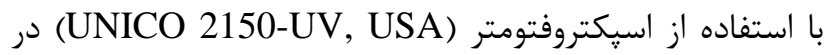

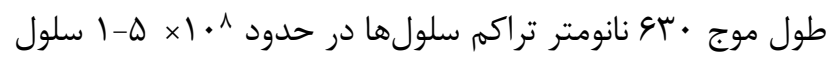

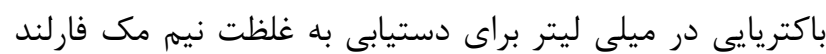
تنظيم و با روش ويبل كانت تاييد شد. يس از تهيه سوسيانسيون

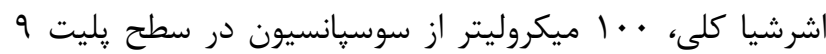

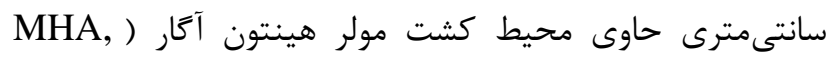
(Merck, Darmstadt, Germany مدت ها دقيقه در زير هود ميكروبيولوزى خشك شد. سيس

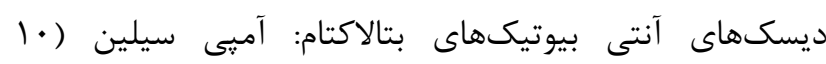

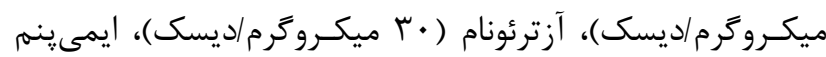

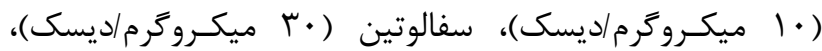

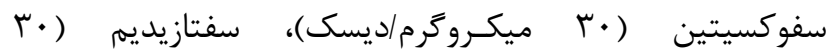

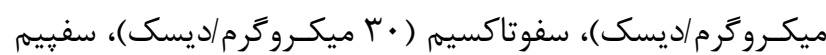

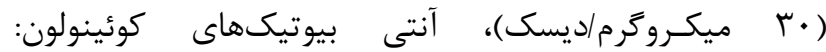

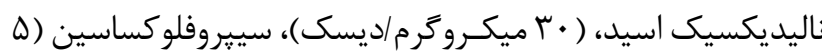

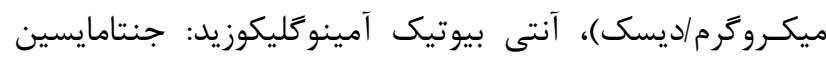

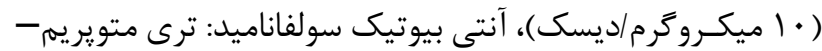

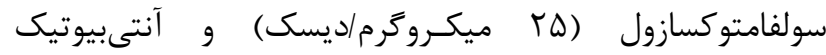

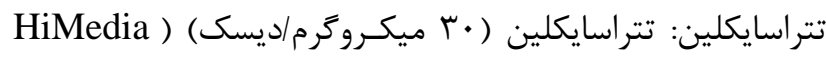
(Laboratories, Mumbai, India يكديگر قرار داده شدند. يليتها به مدت Fr ساعت در rV درجه

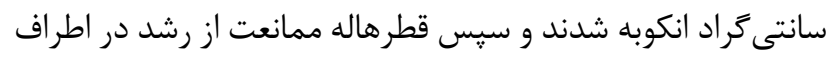
ديسك به وسيله خط كش ميليمترى مورد بررسى قرار گرفت. از ديسك خالى به عنوان كنترل منفى استفاده شد. سيس با جدول

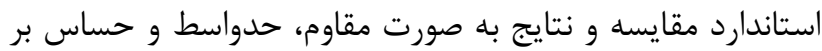


جدول r- شرايط تكثير براى واكنش زنجيرهاى يليمراز.

Table 2. Amplification conditions for PCR.

\begin{tabular}{|c|c|c|c|c|c|}
\hline 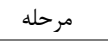 & 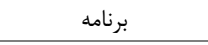 & واسرشت شدن & اتصال يرايمرها & طويلسازى & تعداد جرخه \\
\hline \multirow[t]{2}{*}{ مرحله اول } & دما (درجه سانتى كراد) & $9 F$ & - & - & \multirow[t]{2}{*}{1} \\
\hline & زمان (ثانيه) & $1 r$. & - & - & \\
\hline \multirow[t]{2}{*}{ مرحله دوم } & دما (درجه سانتى كراد) & 94 & (veb,per $) \Delta \Delta$ (ctx-m) $)$ & vr & \multirow[t]{2}{*}{$r \cdot$} \\
\hline & زمان (ثانيه) & $(v e b, p e r) \backslash \Delta,(c t x-m) r \Delta$ & $r$. & $(v e b, p e r) \& \Delta$ (ctx-m) r. & \\
\hline \multirow[t]{2}{*}{ مرحله سوم } & دما (درجه سانتى كراد) & - & - & Vr & \multirow[t]{2}{*}{1} \\
\hline & زمان (ثانيه) & - & - & $4 .$. & \\
\hline
\end{tabular}

خام كاوى) و Escherichia coli Khodavandi-Alizadeh-2 (جدا شده از ينير فرآورى نشده گاوى) در بانك جهانى ثن ثبت شد.

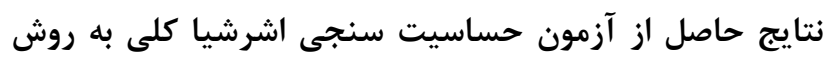
ديسك ديفيوزن الكَى حساسيت آنتىبيوتيكى در بين جدايههاى اشرشيا كلى درئ

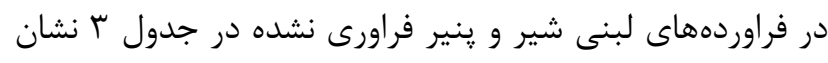

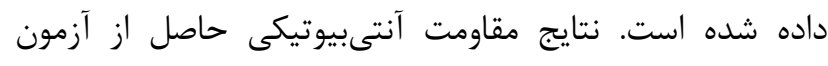

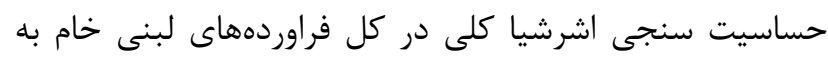

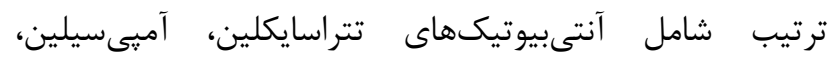

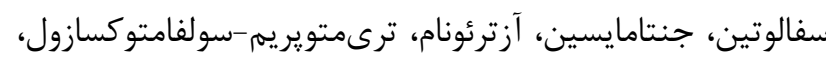

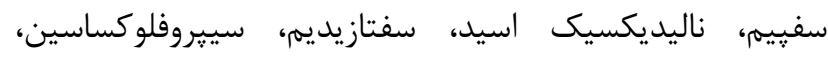

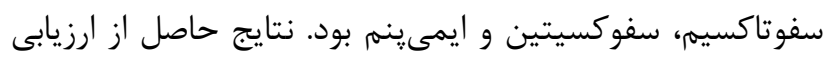

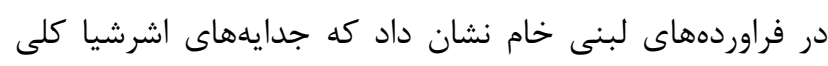

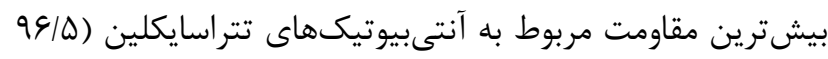

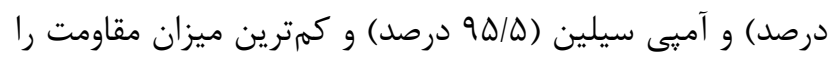

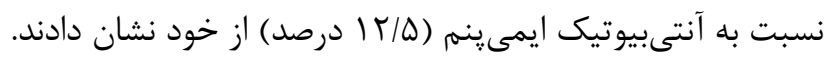

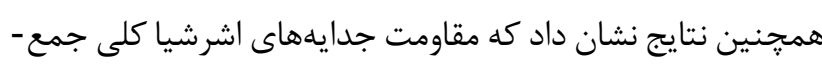

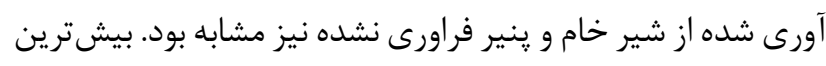

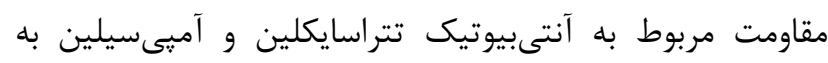

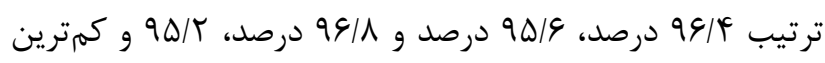

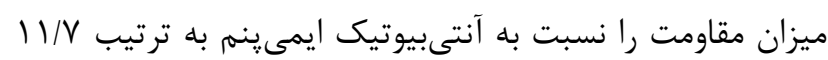

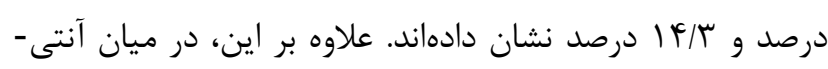

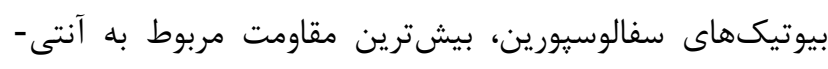

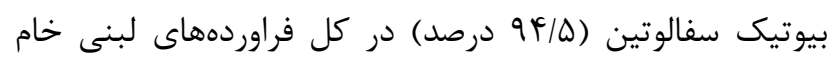

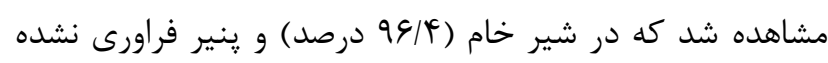

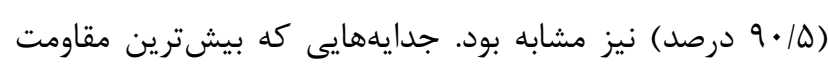

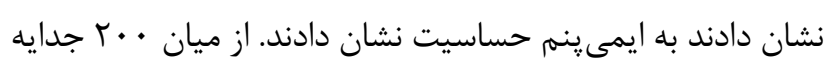

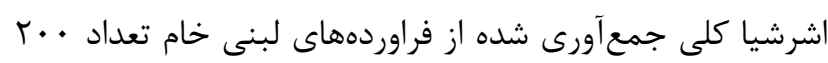

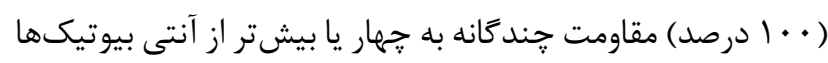

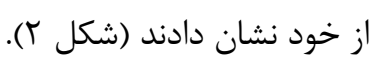

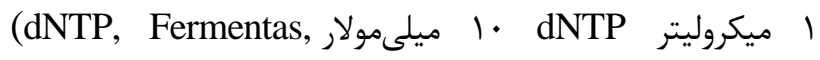
Waltham, MA, USA)

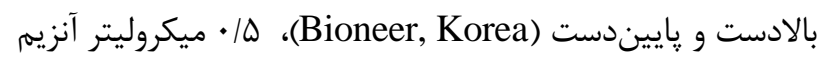

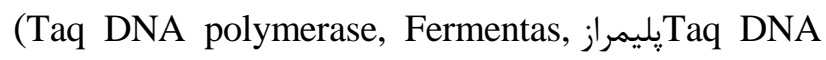
(Waltham, MA, USA)

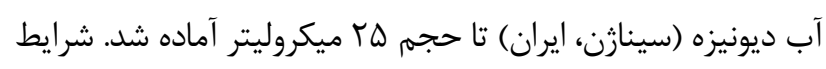

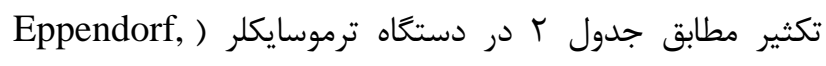
(Germany

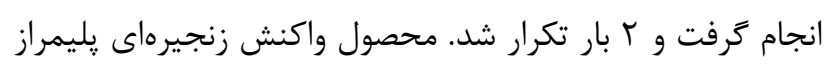

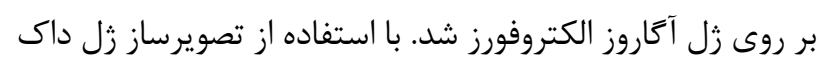
تصوير زل آكاروز ثبت شد. (Bio-Rad, USA) طرح مطالعه و آناليز آمارى اين مطالعه توصسيفى مقطعى به صورت طرح كاملا تصادفى وآئ واري

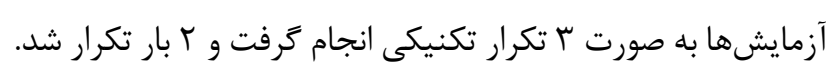

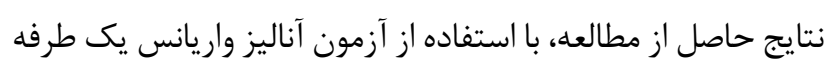

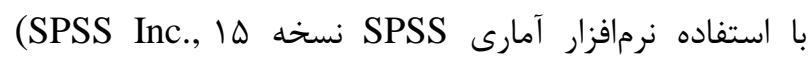
تجزيه و تحليل شد. ارزش Chicago, IL)

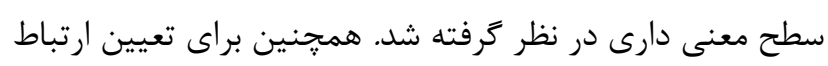
بين گروهها از تست آمارى مجذور كاى استفاده شد.

نتايج

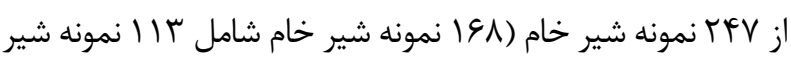

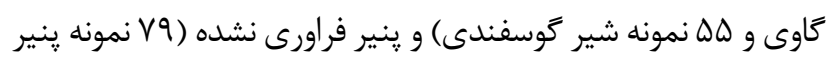

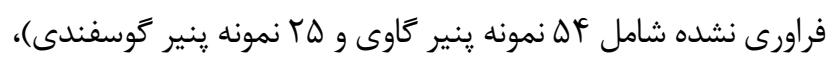

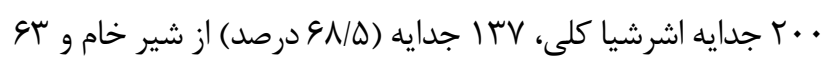

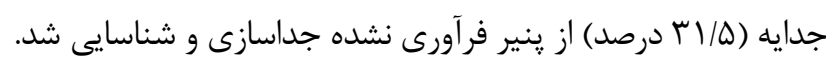

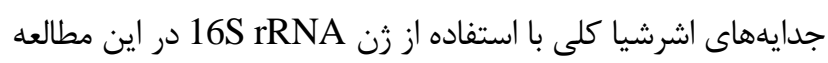
تاييد شد (شكل I A I). توالى زن دو سويه از اشرشيا كلى با شماره

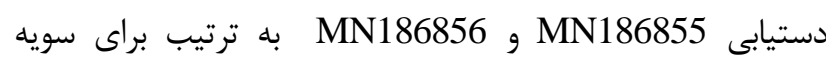
Escherichia coli Khodavandi-Alizadeh-1 


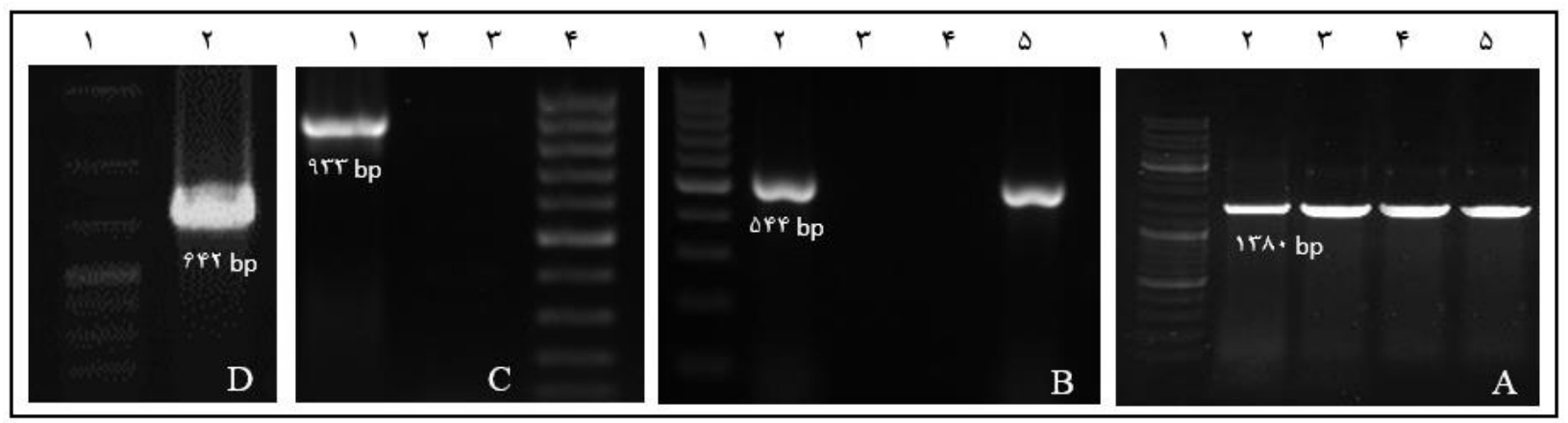

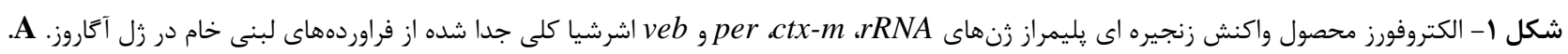

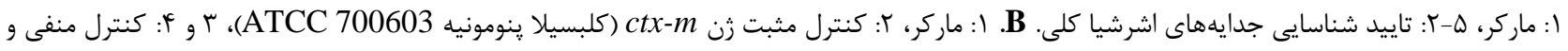

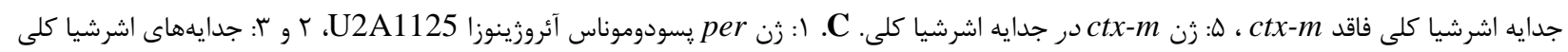

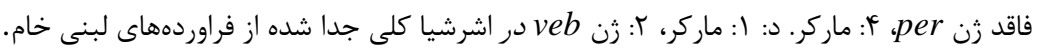

Fig. 1. Gel electrophoresis of PCR products of $r R N A$, ctx-m, per and veb genes in $E$. coli isolated from raw dairy products. A. 1: DNA ladder, 2-5: E. coli isolates. B. 1: DNA ladder, 2: ctx-m positive control (Klebsiella pneumoniae ATCC 700603), 3,4: Negative control and E. coli isolate without $c t x-m$, 5: ctx-m gene in E. coli. C. 1: per gene in Pseudomonas aeruginosa U2A1125, 2,3: E. coli isolates without per,4: DNA ladder. D. 1: DNA ladder, veb gene in E. coli isolated from raw dairy products.

جدول r- الكوى مقاومت آنتى بيوتيكى در جدايههاى اشرشيا كلى در كل فراوردهاى لبنى خام.

Table 3. Antibiotic resistance pattern of E. coli isolated from raw dairy products.

\begin{tabular}{|c|c|c|c|c|c|c|c|c|c|}
\hline & تعداد (درصد) مقاوم & & & تعداد (درصد) & & & تعداد (درصد & & آنتى بيوتيك/ الكوى مقاومت \\
\hline ينير فراورى & شير خام & كل فراورده لبنى & ينير فراورى & شير خام & كل فراورده & نشير فراورى & شير خام & كل فراورده & \\
\hline $\begin{array}{c}4 \cdot \\
(9 \Delta / r)\end{array}$ & $\begin{array}{c}|r| \\
(9 \Delta / 9)\end{array}$ & $\begin{array}{c}191 \\
(9 \Delta / \Delta)\end{array}$ & $\cdot \cdot$ & $\begin{array}{c}1 \\
(\cdot / N r)\end{array}$ & $\begin{array}{c}1 \\
(\cdot / \Delta)\end{array}$ & $\begin{array}{c}r \\
(\xi / \Lambda)\end{array}$ & $\begin{array}{c}\Delta \\
(\mu / N)\end{array}$ & $\begin{array}{l}\wedge \\
\left({ }^{(}\right)\end{array}$ & آميى سيلين \\
\hline $\begin{array}{c}\Delta r \\
(A T / \Delta)\end{array}$ & $\begin{array}{c}1.1 \\
(V / / V)\end{array}$ & $\begin{array}{c}1 \Delta r \\
(V G / \Delta)\end{array}$ & $\begin{array}{l}\cdot \\
(\cdot)\end{array}$ & $\begin{array}{l}11 \\
\text { (^) }\end{array}$ & $\begin{array}{c}11 \\
(\omega / \Delta)\end{array}$ & $\begin{array}{c}11 \\
(I V / \Delta)\end{array}$ & $\begin{array}{l}r \Delta \\
(1 N / r)\end{array}$ & $\begin{array}{l}r 4 \\
(1 \Lambda)\end{array}$ & آزترئونام \\
\hline $\begin{array}{c}9 \\
(1 F / \pi)\end{array}$ & $\begin{array}{c}19 \\
(11 / /)\end{array}$ & $\begin{array}{c}r \Delta \\
(\mid r / \Delta)\end{array}$ & $\begin{array}{c}v \\
(11 / 1)\end{array}$ & $\begin{array}{c}r \mid \\
(1 \Delta / r)\end{array}$ & $\begin{array}{l}r \Lambda \\
(1 F)\end{array}$ & $\begin{array}{c}\& V \\
(V \& / q)\end{array}$ & $\begin{array}{l}1 . . \\
(V r)\end{array}$ & $\begin{array}{c}\mid f V \\
(V \Psi / Q)\end{array}$ & ايمى ينه \\
\hline $\begin{array}{c}\Delta V \\
(q \cdot / \Delta)\end{array}$ & $\begin{array}{l}1 \% T \\
(99 / 4)\end{array}$ & $\begin{array}{l}119 \\
(9 F / 0)\end{array}$ & $\cdot \cdot$ & $\begin{array}{c}1 \\
(\cdot N r)\end{array}$ & $\begin{array}{c}1 \\
(\cdot / 0)\end{array}$ & $\begin{array}{c}9 \\
(9 / D)\end{array}$ & $\begin{array}{c}r \\
(r / q)\end{array}$ & $\begin{array}{l}1 . \\
(\Delta)\end{array}$ & سفالوتين \\
\hline $\begin{array}{c}11 \\
(T N / 9)\end{array}$ & $\begin{array}{c}r \wedge \\
(r V / V)\end{array}$ & $\begin{array}{l}\Delta \varphi \\
(\ulcorner\Lambda)\end{array}$ & $\begin{array}{c}r \\
r / r)\end{array}$ & $\begin{array}{c}11 \\
(1 \% / 1)\end{array}$ & $\begin{array}{l}r \cdot \\
(1 \cdot)\end{array}$ & $\begin{array}{c}r \mu \\
(9 N / r)\end{array}$ & $\begin{array}{c}11 \\
(\Delta 9 / 1)\end{array}$ & $\begin{array}{l}\text { IFF } \\
(g r)\end{array}$ & سفوكسيتين \\
\hline $\begin{array}{c}r F \\
(r N / I)\end{array}$ & $\begin{array}{c}V V \\
(\Delta g / T)\end{array}$ & $\begin{array}{c}1.1 \\
(\Delta \cdot / \Delta)\end{array}$ & $\begin{array}{l}\text { IV } \\
(T V)\end{array}$ & $\begin{array}{l}\text { YF } \\
(I V / \Delta)\end{array}$ & $\begin{array}{c}4 \mid \\
(r \cdot \mid \Delta)\end{array}$ & $\begin{array}{c}r r \\
(r / q)\end{array}$ & $\begin{array}{c}r q \\
(r 9 / \%)\end{array}$ & $\begin{array}{l}\Delta \wedge \\
(Y q)\end{array}$ & سفتازيديم \\
\hline $\begin{array}{l}r f \\
(\Delta f)\end{array}$ & $\begin{array}{l}\Delta \cdot \\
(+9 / \theta)\end{array}$ & $\begin{array}{l}\text { AF } \\
(F r)\end{array}$ & $\begin{array}{l}1 \cdot \\
(10 / 9)\end{array}$ & $\begin{array}{c}\text { IV } \\
(\mid T / F)\end{array}$ & $\begin{array}{c}r V \\
(\mid r / Q)\end{array}$ & $\begin{array}{c}19 \\
(r \cdot / r)\end{array}$ & $\begin{array}{l}V \cdot \\
(\Delta) / 1)\end{array}$ & $\begin{array}{c}19 \\
(F+/ \Delta)\end{array}$ & سفوتاكسيم \\
\hline $\begin{array}{l}F r \\
(99 / V)\end{array}$ & $\begin{array}{c}9 V \\
(V \cdot / A)\end{array}$ & $\begin{array}{l}149 \\
(99 / \Delta)\end{array}$ & $\begin{array}{c}\Delta \\
(v / 9)\end{array}$ & $\begin{array}{c}\Delta \\
(\Psi / N)\end{array}$ & $\begin{array}{l}1 \cdot \\
(\Delta)\end{array}$ & $\begin{array}{c}19 \\
\left(r \Delta / \varphi^{\prime}\right)\end{array}$ & $\begin{array}{l}r \Delta \\
r \Delta / q)\end{array}$ & $\begin{array}{c}\Delta 1 \\
(T \Delta / \Delta)\end{array}$ & سفييم \\
\hline $\begin{array}{c}r V \\
(\Delta \Lambda / V)\end{array}$ & $\begin{array}{l}9 . \\
(\varphi \Delta / v)\end{array}$ & $\begin{array}{l}I T V \\
(g r / \Delta)\end{array}$ & $\begin{array}{c}r \\
(\kappa / \Lambda)\end{array}$ & $\begin{array}{l}\text { IT } \\
(N / A)\end{array}$ & $\begin{array}{c}10 \\
(V / Q)\end{array}$ & $\begin{array}{c}r r \\
(r g / \Delta)\end{array}$ & $\begin{array}{c}r \Delta \\
r \Delta / \varphi)\end{array}$ & $\begin{array}{l}\Delta \wedge \\
(\ulcorner q)\end{array}$ & ن ناليديكسيك اسيد \\
\hline $\begin{array}{c}\text { If } \\
(r / r)\end{array}$ & $\begin{array}{c}V r \\
(\Delta r / r)\end{array}$ & $\begin{array}{c}A V \\
(\& r / \Delta)\end{array}$ & $\begin{array}{c}9 \\
(9 / \Delta)\end{array}$ & $\begin{array}{c}9 \\
(9 / 9)\end{array}$ & $\begin{array}{c}10 \\
(V / Q)\end{array}$ & $\begin{array}{c}r r \\
(9 N / r)\end{array}$ & $\begin{array}{c}\Delta \Delta \\
(\psi \cdot / 1)\end{array}$ & $\begin{array}{l}91 \\
(49)\end{array}$ & سييروفلوكساسين \\
\hline $\begin{array}{c}r q \\
(91 / 9)\end{array}$ & $\begin{array}{l}110 \\
(\Lambda r / 9)\end{array}$ & $\begin{array}{l}\text { lof } \\
(V Y)\end{array}$ & $\begin{array}{c}1 . \\
(10 / 9)\end{array}$ & $\begin{array}{c}11 \\
(\mid r / 1)\end{array}$ & $\begin{array}{l}r \wedge \\
(I f)\end{array}$ & $\begin{array}{l}\text { If } \\
(T r / T)\end{array}$ & $\begin{array}{c}F \\
(T / 9)\end{array}$ & $\begin{array}{l}11 \\
\text { (9) }\end{array}$ & جنتامايسين \\
\hline $\begin{array}{c}r \Delta \\
(r q / v)\end{array}$ & $\begin{array}{c}11 V \\
\left(\Lambda \Delta / \Psi^{\leftarrow}\right)\end{array}$ & $\begin{array}{l}\text { IFT } \\
\text { (VI) }\end{array}$ & $\begin{array}{c}r \\
r / r)\end{array}$ & $\begin{array}{c}9 \\
(f / 4)\end{array}$ & $\begin{array}{c}\wedge \\
\left(\varphi^{*}\right)\end{array}$ & $\begin{array}{c}r q \\
(\Delta V / I)\end{array}$ & $\begin{array}{l}1 f \\
(1 \cdot / r)\end{array}$ & $\begin{array}{l}\Delta \cdot \\
(r \Delta)\end{array}$ & ترىمتويريم-سولفامتوكسازول \\
\hline $\begin{array}{l}91 \\
(99 / 1)\end{array}$ & $\begin{array}{c}\text { IrT } \\
(Q \& / 4)\end{array}$ & $\begin{array}{c}194 \\
(99 / 0)\end{array}$ & $\dot{\cdot}$ & $\begin{array}{c}1 \\
(\cdot N r)\end{array}$ & $\begin{array}{c}1 \\
(\cdot / 0)\end{array}$ & $\begin{array}{c}r \\
(r / r)\end{array}$ & $\begin{array}{c}r \\
(T / 9)\end{array}$ & $\begin{array}{l}9 \\
(r)\end{array}$ & تتراسايكلين \\
\hline
\end{tabular}




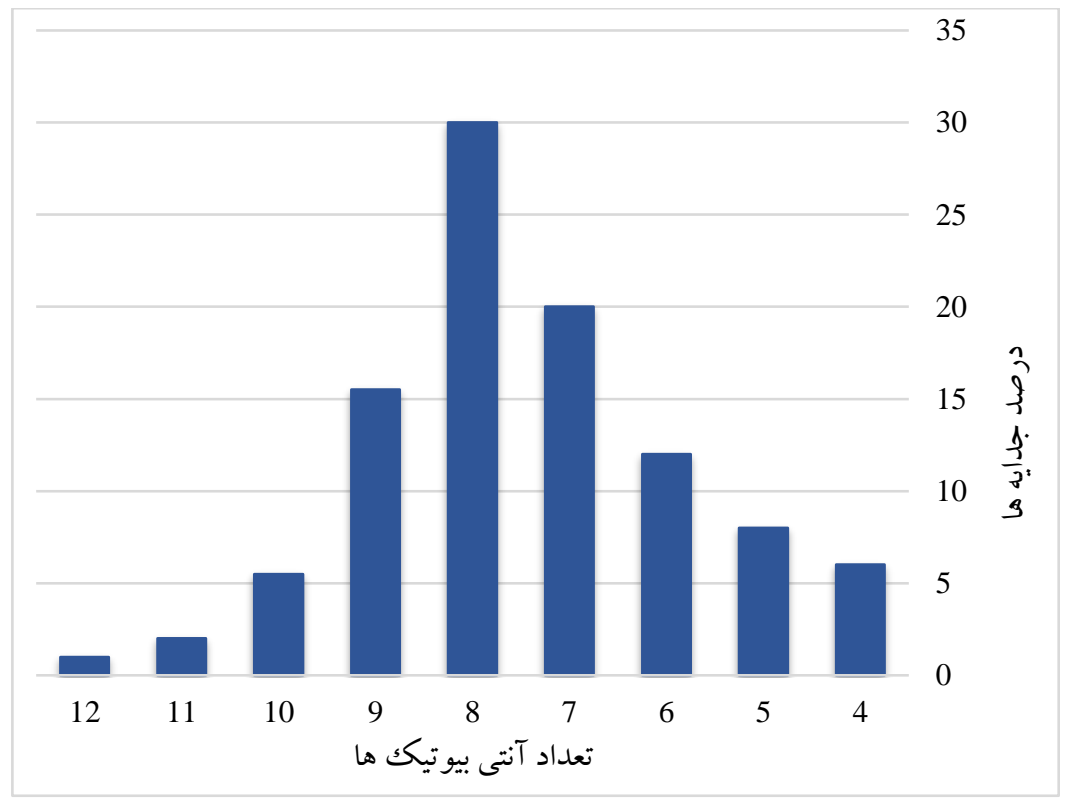

شكل r- درصد مقاومت جندتايى اشرشيا كلى جدا شده از فراوردهاى لبنى خام.

Fig. 2. The percentage of multidrug resistance of $E$. coli isolates, isolated from raw dairy products.

مقاوم اشرشيا كلى مولد بتالاكتاماز طيف گسترده در نمونههاى شير خام و ينير فراورى نشده مشاهده نكرديد (جدول هالم).

بحث

مطالعه حاضر براى ارزيابى فنوتيبى و زنوتيبى جدايههاى اشرشيا كلى توليد كننده بتالاكتاماز طيف گسترده از فرائ فراوردهـ هاى لبنى خام در ياسوج طراحى شده است. امروزه

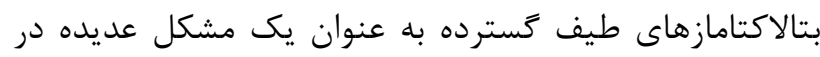
مركز بالينى انسانى و حيوانى در سراسر جهان مطان مطرح است. شيوع اشرشيا كلى حاوى بتالاكتامازهاى طيف كسترده دئ در بر بين

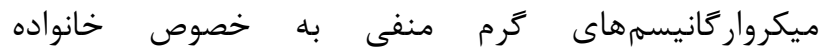
انتروباكترياسه در مناطق مختلف جغر افيايى سراسر جهان منان و در

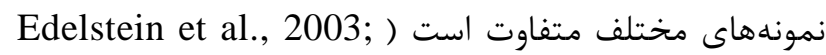
Doi et al., 2010; Zamani et al., 2015; Braun et al., 2016). نتايج حاصل از مطالعه حاضر نشان داد كه نمونههاى

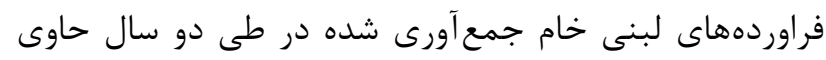

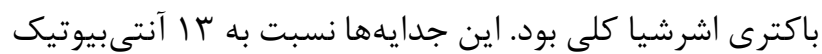

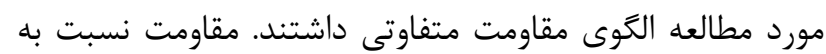

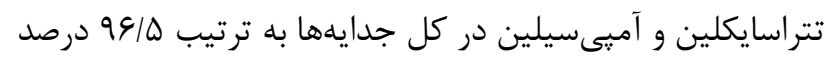

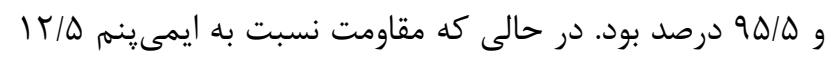

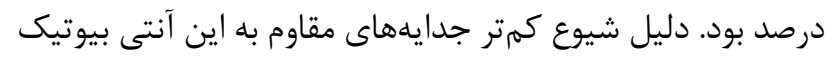

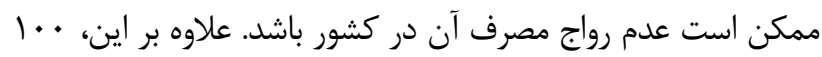

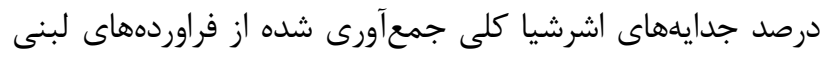

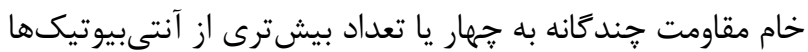

نتايج حاصل از آزمون تاييدى فنوتييى اشرشيا كلى توليدكننـــده

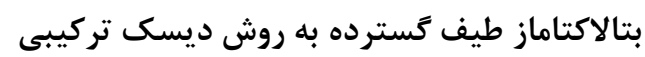
نتايج حاصل از آزمون تاييدى فنوتييى اشرشيا كلى توليدكنيــنده بتالاكتاماز طيف كسترده به روش ديسك تركيبى نشان داد كه

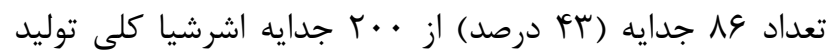

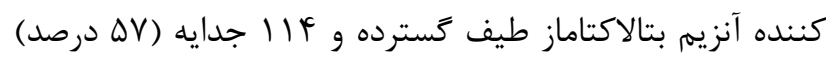

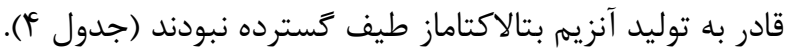

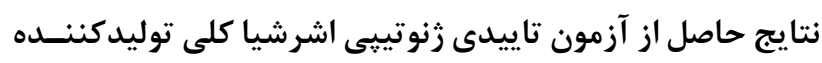

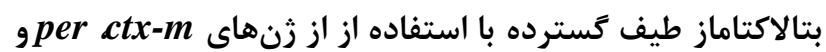
veb

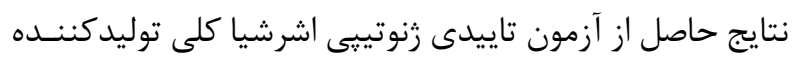

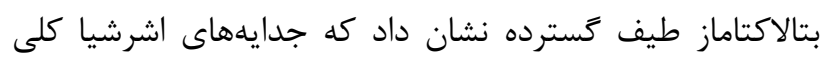

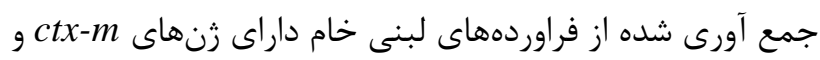

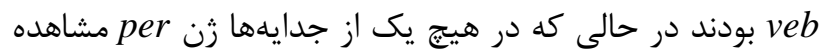

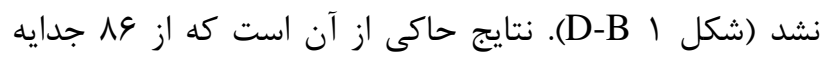

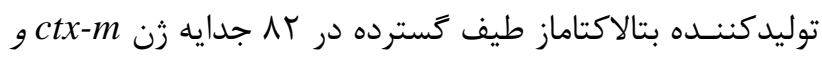
در V جدايه زن veb مشاهده شد علاوه بر اين نتايج نشان داد كه

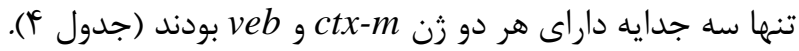

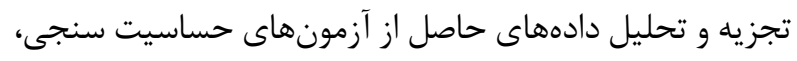
فنوتيبى و زنوتيبى نشان داد كه جدايههاى اشرشيا كلى توليد

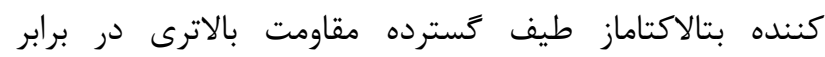

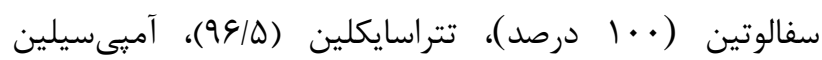

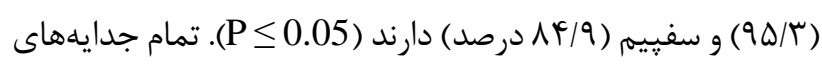
اشرشيا كلى مولد بتالاكتاماز طيف كسترده به ايمىينهم حساس

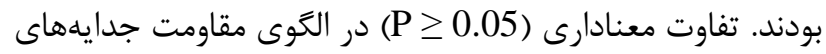




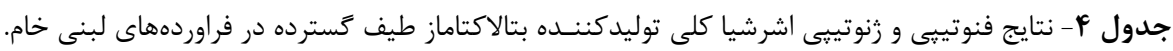

Table 4. Phenotype and genotype results of E. coli producing extended-spectrum $\beta$-lactamases in raw dairy products.

\begin{tabular}{|c|c|c|c|}
\hline ينير فراورى نشده & 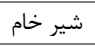 & كل فراورده لبنى & جدايههاى اشرشيا كلى \\
\hline rr & $\Delta F$ & $\wedge \varsigma$ & توليد كننده آنزيم بتالاكتاماز طيف كسترده \\
\hline rT & $\Delta$. & NT & $c t x-m$ \\
\hline$\cdot$ & . & . & per \\
\hline 1 & 9 & v & $v e b$ \\
\hline
\end{tabular}

جدول هـ الكَى مقاومت آنتىبيوتيكى در جدايههاى اشرشيا كلى توليدكنــده بتالاكتاماز طيف گسترده در فراوردهاى لبنى خام.

Table 5. Antibiotic resistance pattern of E. coli producing extended-spectrum $\beta$-lactamases in raw dairy products.

\begin{tabular}{|c|c|c|c|c|c|c|c|c|c|}
\hline & تعداد (درصد) & & & حداد (درصد) حدواسط & & & داد (درصد & & آنتى بيوتيك/ الكَوى مقاومت \\
\hline ينير & 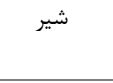 & كل فراورده & بنير & شير & كل فراورده & ينير & شير & كل فرآورده & \\
\hline $\begin{array}{c}r \cdot \\
(9 / / \Lambda)\end{array}$ & $\begin{array}{c}\Delta V T \\
(Q 9 / \Gamma)\end{array}$ & $\begin{array}{c}\wedge r \\
(q \Delta / r)\end{array}$ & $\dot{\cdot} \cdot$ & $\cdot \vec{\cdot}$ & $\cdot \cdot$ & $\begin{array}{c}r \\
(g / r)\end{array}$ & $\begin{array}{c}r \\
r / v)\end{array}$ & $\begin{array}{c}F \\
(F / V)\end{array}$ & آمبىسيلين \\
\hline $\begin{array}{l}r F \\
(V Q)\end{array}$ & $\begin{array}{c}r q \\
(V T / Y)\end{array}$ & $\begin{array}{c}g r \\
(V T / Y)\end{array}$ & $\dot{\cdot} \cdot$ & $\begin{array}{c}11 \\
\left(r \cdot / \varphi^{4}\right)\end{array}$ & $\begin{array}{c}11 \\
(1 / / \Lambda)\end{array}$ & $\begin{array}{c}\wedge \\
(T \Delta)\end{array}$ & $\begin{array}{c}F^{k} \\
(V / F)\end{array}$ & $\begin{array}{l}\text { Ir } \\
(I f)\end{array}$ & آزترئونام \\
\hline$\dot{\cdot}$ & $\dot{\cdot} \cdot(\cdot)$ & $\cdot \vec{\cdot}$ & $\dot{\cdot}$ & $\dot{\cdot} \cdot$ & $\dot{\cdot} \cdot(\cdot)$ & $\begin{array}{l}r r \\
(1 \cdots)\end{array}$ & $\begin{array}{l}\Delta F \\
(1 \cdots)\end{array}$ & $\begin{array}{c}\wedge \varepsilon \\
(1 \cdots)\end{array}$ & ايمى ينه \\
\hline $\begin{array}{c}\text { rr } \\
(1 \cdots)\end{array}$ & $\begin{array}{c}\Delta F \\
(1 \cdot \cdot)\end{array}$ & $\begin{array}{c}\wedge \varepsilon \\
(1 \cdot \cdots)\end{array}$ & $\dot{(\cdot)}$ & $\dot{\cdot}$ & $\begin{array}{l}\cdot \\
(\cdot)\end{array}$ & $\cdot \vec{\cdot}$ & $\begin{array}{l}\cdot \\
(\cdot)\end{array}$ & $\begin{array}{l}\cdot \\
(\cdot)\end{array}$ & سفالوتين \\
\hline $\begin{array}{c}10 \\
(\$ \& / 9)\end{array}$ & $\begin{array}{c}r \Delta \\
(\varphi g / r)\end{array}$ & $\begin{array}{c}r \cdot \\
(\varphi / \theta)\end{array}$ & $\begin{array}{c}1 \\
(r / 1)\end{array}$ & $\begin{array}{c}1 \cdot \\
(\mid N / \Delta)\end{array}$ & $\begin{array}{c}11 \\
(I r / \Lambda)\end{array}$ & $\begin{array}{l}19 \\
(\Delta \cdot)\end{array}$ & $\begin{array}{c}19 \\
(r \Delta / r)\end{array}$ & $\begin{array}{c}r \Delta \\
(\tau \cdot / v)\end{array}$ & سفوكسيتين \\
\hline $\begin{array}{c}11 \\
(\Delta \& / K)\end{array}$ & $\begin{array}{c}r l \\
(\Delta V / F)\end{array}$ & $\begin{array}{l}p q \\
(\Delta V)\end{array}$ & $\begin{array}{c}\Delta \\
(\mid Q / 9)\end{array}$ & $\begin{array}{c}\wedge \\
(\mid f / \Lambda)\end{array}$ & $\begin{array}{l}1 \pi \\
(1 Q)\end{array}$ & $\begin{array}{c}9 \\
(T N / I)\end{array}$ & $\begin{array}{l}10 \\
(T V / \Lambda)\end{array}$ & $\begin{array}{l}r F \\
(r \Lambda)\end{array}$ & سفتازيديم \\
\hline $\begin{array}{c}11 \\
(\Delta G / T)\end{array}$ & $\begin{array}{c}r q \\
(\Delta r / V)\end{array}$ & $\begin{array}{c}F V \\
(\Delta F / V)\end{array}$ & $\begin{array}{c}\Delta \\
(|Q| q)\end{array}$ & $\begin{array}{c}9 \\
(\mid 9 / V)\end{array}$ & $\begin{array}{c}\mid f \\
(\mid \varepsilon / Y)\end{array}$ & $\begin{array}{c}9 \\
(T N / 1)\end{array}$ & $\begin{array}{c}19 \\
((79 / 8)\end{array}$ & $\begin{array}{c}r \Delta \\
(r q / 1)\end{array}$ & سفوتاكسيم \\
\hline $\begin{array}{c}\varphi \\
(\Lambda 1 / r)\end{array}$ & $\begin{array}{l}q V \\
\text { (AV) }\end{array}$ & $\begin{array}{c}V r \\
(\Delta F / q)\end{array}$ & $\begin{array}{c}r \\
(q / f)\end{array}$ & $\begin{array}{c}r \\
(\Delta / 9)\end{array}$ & $\begin{array}{l} \\
\text { (V) }\end{array}$ & $\begin{array}{c}r \\
(q / 4)\end{array}$ & $\begin{array}{c}c^{r} \\
(V / f)\end{array}$ & $\begin{array}{c}V \\
(N / 1)\end{array}$ & سفييم \\
\hline $\begin{array}{l}r \cdot \\
(q r / \Delta)\end{array}$ & $\begin{array}{l}r F \\
(q \mu)\end{array}$ & $\begin{array}{l}\Delta F \\
(G / / \Lambda)\end{array}$ & $\begin{array}{c}r \\
(g / r)\end{array}$ & $\begin{array}{l}V \\
\text { (Ir) }\end{array}$ & $\begin{array}{c}9 \\
(1 \cdot / 0)\end{array}$ & $\begin{array}{c}1 \cdot \\
(r / / r)\end{array}$ & $\begin{array}{c}I r \\
(T F / 1)\end{array}$ & $\begin{array}{l}r r \\
(r g / V)\end{array}$ & ناليديكسيك اسيد \\
\hline $\begin{array}{c}19 \\
(\Delta 9 / 4)\end{array}$ & $\begin{array}{c}r \mid \\
\left(\Delta V / \varphi^{\epsilon}\right)\end{array}$ & $\begin{array}{l}\Delta \cdot \\
(\Delta \wedge)\end{array}$ & $\begin{array}{c}F \\
(\mid T / Q)\end{array}$ & $\begin{array}{c}\wedge \\
(\mid f / \Lambda)\end{array}$ & $\begin{array}{l}\text { Ir } \\
\text { (If) }\end{array}$ & $\begin{array}{c}9 \\
(T N / I)\end{array}$ & $\begin{array}{c}10 \\
(T Y / \Lambda)\end{array}$ & $\begin{array}{l}r^{F} \\
(T \wedge)\end{array}$ & سييروفلوكساسين \\
\hline $\begin{array}{c}r r \\
(V / / q)\end{array}$ & $\begin{array}{c}r \cdot \\
(v e / 1)\end{array}$ & $\begin{array}{c}g r \\
(V T / r)\end{array}$ & $\dot{\cdot}$ & $\begin{array}{c}1 \cdot \\
(\mid N / Q)\end{array}$ & $\begin{array}{l}1 . \\
(11 / 9)\end{array}$ & $\begin{array}{c}9 \\
(T N / 1)\end{array}$ & $\begin{array}{c}r \\
(V / F)\end{array}$ & $\begin{array}{c}1 \% \\
(1 D / 1)\end{array}$ & جنتامايسين \\
\hline $\begin{array}{c}r \mid \\
(90 / 9)\end{array}$ & $\begin{array}{c}r V \\
(\Phi N / \Delta)\end{array}$ & $\begin{array}{c}\Delta \wedge \\
\left(\Phi \vee / \Psi^{\varepsilon}\right)\end{array}$ & $\begin{array}{c}r \\
(g / r)\end{array}$ & $\begin{array}{c}\Delta \\
(9 / 4)\end{array}$ & $\begin{array}{c}V \\
(N / 1)\end{array}$ & $\begin{array}{c}9 \\
(T N / 1)\end{array}$ & $\begin{array}{c}\text { IT } \\
(T r / T)\end{array}$ & $\begin{array}{c}r l \\
\left(r / / \Psi^{*}\right)\end{array}$ & ترىمتويريم-سولفامتوكسازول \\
\hline $\begin{array}{c}r \cdot \\
(q \pi / \Lambda)\end{array}$ & $\begin{array}{c}\Delta r \\
(9 / / 1)\end{array}$ & $\begin{array}{c}\Delta r \\
(9 \varphi / Q)\end{array}$ & $\dot{\cdot} \cdot$ & $\cdot \cdot$ & $\cdot \vec{\cdot}$ & $\begin{array}{c}r \\
(g / r)\end{array}$ & $\begin{array}{c}1 \\
(1 / 9)\end{array}$ & $\begin{array}{c}r \\
r / \Delta)\end{array}$ & تتراسايكلين \\
\hline
\end{tabular}

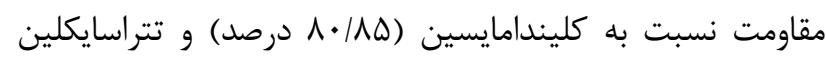

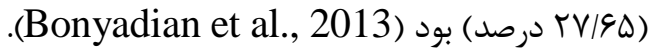

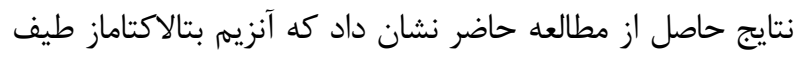

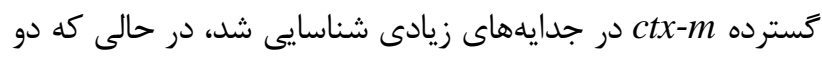

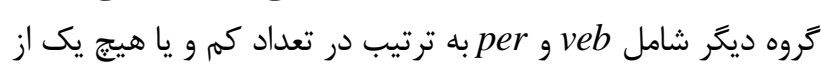

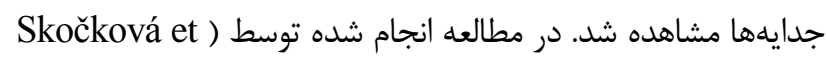
(al., 2015

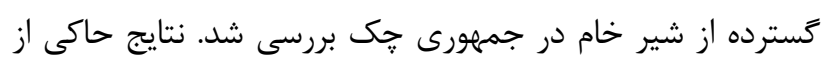

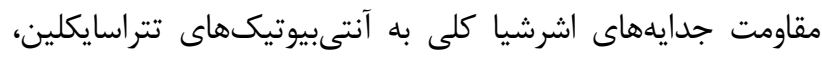

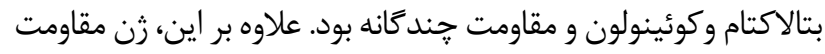

را از خود نشان دادند. اصولا باكترىهاى توليدكننده بتالاكتامازهاى

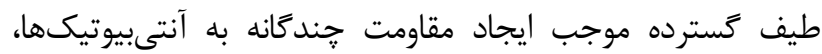
شكست درمانى و مشكلات عديده در درمان شدهاند ( Edelstein et al., 2003; Snow et al., 2012; Schmid et al., 2013; Braun et al., 2016 (et مطالعات نشان داده كه اشرشيا كلى توليد كننده بتالاكتامازهاى طيف گسترده از حيوانات توليد كننده مواد لبنى و

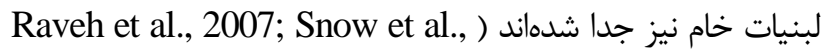
(2012; Vrabec et al., 2015; Kürekci et al., 2016 بيان كردند كه از •له جدايه اشريشيا كلى، FV جدايه (F أq درصد) نسبت به يك يا جند آنتىبيوتيك مقاومت نشان دادند و بيشترين إندان 


\section{REFERENCES}

Bonnet, R. 2004. Growing group of extended-spectrum $\beta$ lactamases: the CTX-M enzymes. Antimicrob. Agents Chemother. 48: 1-14.

Bonyadian, M., Ebrahimi, A. \& Jamali, M. 2013. Study on the antibiotic resistance of $E$. coli isolated from raw milk and unpasteurized cheese and survey on resistance transmission to $E$. coli $\mathrm{O} 2$ : $\mathrm{K} 12$. Iranian $\mathrm{J}$. Vet. Sci. 7: 26-31.

Braun, S.D., Ahmed, M.F., El-Adawy, H., Hotzel, H., Engelmann, I., Weiß, D., Monecke, S. \& Ehricht, R. 2016. Surveillance of extended-spectrum beta-lactamaseproducing Escherichia coli in dairy cattle farms in the Nile Delta, Egypt. Front Microbiol. 7: 1-14.

Clinical Laboratory Standards Institute (CLSI). 2014. Performance standards for antimicrobial susceptibility testing; Supplement $\mathrm{M}_{100}-\mathrm{S}_{24}$.

Doi, Y., Paterson, D.L., Egea, P., Pascual, A., LopezCerero, L., Navarro, M.D., Adams-Haduch, J.M., Qureshi, Z.A., Sidjabat, H.E. \& Rodriguez-Bano, J. 2010. Extended-spectrum and CMY-type betalactamase-producing Escherichia coli in clinical samples and retail meat from Pittsburgh, USA and Seville, Spain. Clin. Microbiol. Infect. 16: 33-38.

Edelstein, M., Pimkin, M., Palagin, I., Edelstein, I. \& Stratchounski, L. 2003. Prevalence and molecular epidemiology of CTX-M extended-spectrum betalactamase-producing Escherichia coli and Klebsiella pneumoniae in Russian hospitals. Antimicrob. Agents Chemother. 47: 3724-3732.

Geser, N., Stephan, R. \& Hächler, H. 2012. Occurrence and characteristics of extended-spectrum $\beta$-lactamase (ESBL) producing Enterobacteriaceae in food producing animals, minced meat and raw milk. BMC Vet. Res. 8: 21

Holoda, E., Vu-Khac, H., Andraskova, S., Chomova, Z., Wantrubova, A., Krajnak, M. \& Pilipcinec, E. 2005. PCR assay for detection and differentiation of $\mathrm{K} 88 \mathrm{ab}(1)$, K88ab(2), K88ac, and K88ad fimbrial adhesins in E. coli strains isolated from diarrheic piglets. Folia Microbiol (Praha) 50: 107-112.

Jiang, X., Zhang, Z., Li, M., Zhou, D., Ruan, F. \& Lu, Y. 2006. Detection of extended-spectrum beta-lactamases in clinical isolates of Pseudomonas aeruginosa. Antimicrob. Agents Chemother. 50: 2990-2995.

Kim, S., Hu, J., Gautom, R., Kim, J., Lee, B. \& Boyle, D.S. 2007. CTX-M extended-spectrum $\beta$-lactamases, Washington State. Emerg. Infect. Dis. 13: 513-516.

Kurekci, C., Arkadaş, M. \& Avsar, Y.K. 2016. Occurrence, genetic characterization and antimicrobial resistance of extended spectrum $\beta$-lactamase producing Escherichia coli isolated from Sürk samples, a traditional Turkish cheese. J. Food Meas. Charact. 10: 709-714.

Raveh, D., Yinnon, A.M., Broide, E. \& Rudensky, B. 2007. Susceptibilities of ESBL-producing Enterobacteriaceae to ertapenem, meropenem and piperacillintazobactam with and without clavulanic acid. Chemotherapy 53: 185-189.
در جدايههاى توليدكننده بتالاكتامازهاى طيف گسترده ctx-m مشاهده شد. يزوهشگران اشرشيا كلى توليدكننده بتالاكتامازهاى طيف گسترده را از نمونههاى ينير سورك سنتى تركيه جدا كردند Kürekci et al., 2016)

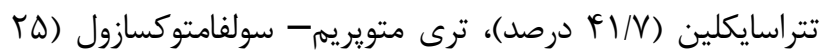

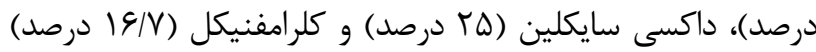
مقاومت نشان دادند. در مطالعه مذكور جداسازى و شناسايى تعداد زياد اشرشيا كلى توليد كننده بتالاكتامازهاى طيف كسترده از ينير سورك سنتى تركيه مى تواند منبع انتقال آلودگى قابل ملاحظه براى انسان ها باشد.

مطالعات نشان داده كه مصرف بىرويه آنتىبيوتيكها در در علوم يزشكى و علوم دامى موجب گسترش باكترىهاى مقاوم به آنتى - مانى بيوتيكهاى مختلف شده است. مقاومت باكترىها توليد كننده بتالاكتاماز طيف گسترده به عنوان يك تهديد بزرى در مصرف آنتى بيوتيكها به شمار مىرود. انتقال زنهاى مرتبط با بتالاكتاماز طيف گسترده از حيوان به انسان از طريق زنجيره غذايى و يا تماس مستقيم انجام مىشود. مطالعه حاضر حاكى از آن است كه فراورده -

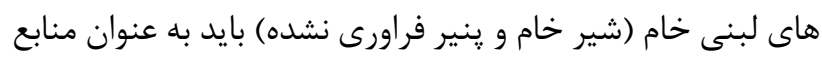
زنتيكى انتقال اشرشيا كلى توليد كننده بتالاكتاماز طيف كسترده در نظر گرفته شوند. با توجه به عرضه و مصرف فراوان شير خام و ينير فراورى نشده در شهر ياسوج، يافتههاى حاضر نشان مىدهد كه فراوردههاى لبنى خام ممكن است مخازنى براى انتشار آنتىبيوتيك-

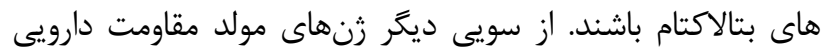
هتانسيل انتقال به انسان را خواهند داشت كه اين امر در سلامتى و

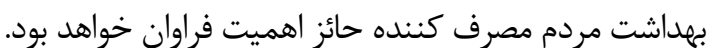

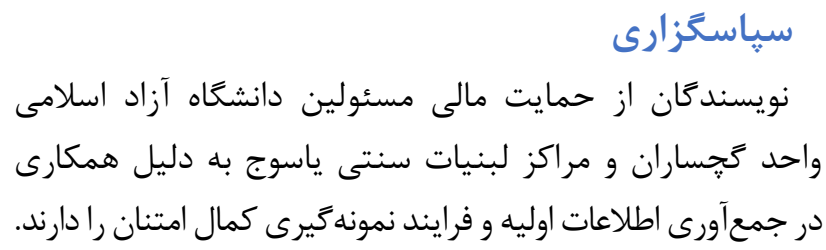


Rawat, D. \& Nair, D. 2010. Extended-spectrum $\beta$ lactamases in gram negative bacteria. J. Glob Infect. Dis. 2: 263-274.

Rupp, M.E. \& Fey, P.D. 2003. Extended spectrum betalactamase (ESBL)-producing Enterobacteriaceae: considerations for diagnosis, prevention and drug treatment. Drugs 63: 353-365.

Schmid, A., Hormansdorfer, S., Messelhäusser, U., Kasbohrer, A., Sauter-Louis, C. \& Mansfeld, R. 2013. Prevalence of extended-spectrum $\beta$-lactamaseproducing Escherichia coli on Bavarian dairy and beef cattle farms. Appl. Environ. Microbiol. 79: 3027-3032.

Shaikh, S., Fatima, J., Shakil, S., Rizvi, S.M. \& Kamal, MA. 2015. Antibiotic resistance and extended spectrum beta-lactamases: types, epidemiology and treatment. Saudi J. Biol. Sci. 22: 90-101.

Skockova, A., Bogdanovicova, K., Kolackova, I., Karpískova, R. 2015. Antimicrobial-resistant and extended-spectrum $\beta$-lactamase-producing Escherichia coli in raw cow's milk. J. Food Protect. 78: 72-77.
Snow, L.C., Warner, R.G., Cheney, T., Wearing, H., Stokes, M., Harris, K., Teale, C. J. \& Coldham, N.G. 2012. Risk factors associated with extended spectrum beta-lactamase Escherichia coli (CTX-M) on dairy farms in North West England and North Wales. Prev. Vet. Med. 106: 225-234.

Suardana, I.W. 2014. Analysis of nucleotide sequences of the 16S rRNA gene of novel Escherichia coli strains isolated from feces of human and bali cattle. J. Nucleic Acids 2014: 1-7.

Vrabec, M., Lovayova, V., Dudrikova, K., Gallo, J. \& Dudrikova, E. 2015. Antibiotic resistance and prevalence of Enterococcus spp. and Escherichia coli isolated from Bryndza cheese. Italian J. Anim. Sci. 14: 609-614.

Zamani, K., Emami, A., Bazargani, A. \& Moattari, A. 2015. Phenotypic and molecular characterization of CTX-M extended-spectrum beta-lactamase-producing Escherichia coli isolates in Shiraz, Iran. Rev. Soc. Bras. Med. Trop. 48: 479-482.

How to cite this article:

Khodavandi, P., Alizadeh, F., \& Khodavandi, A. 2020. The multidrug resistance and production of extended-spectrum beta-lactamases $c t x-m$, per and ver in Escherichia coli isolates derived from raw dairy samples. Nova Biologica Reperta 7: 46-54. (In Persian).

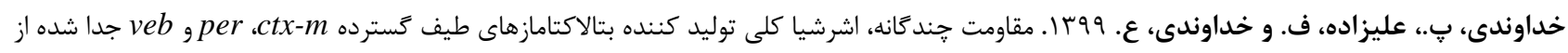

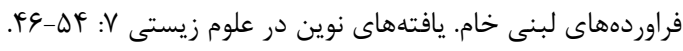

